\title{
Determinación de indicadores de contaminación fecal (coliformes fecales) en los tanques de abastecimiento de agua de la Universidad Distrital Francisco José de Caldas Sedes Macarena a y b*
}

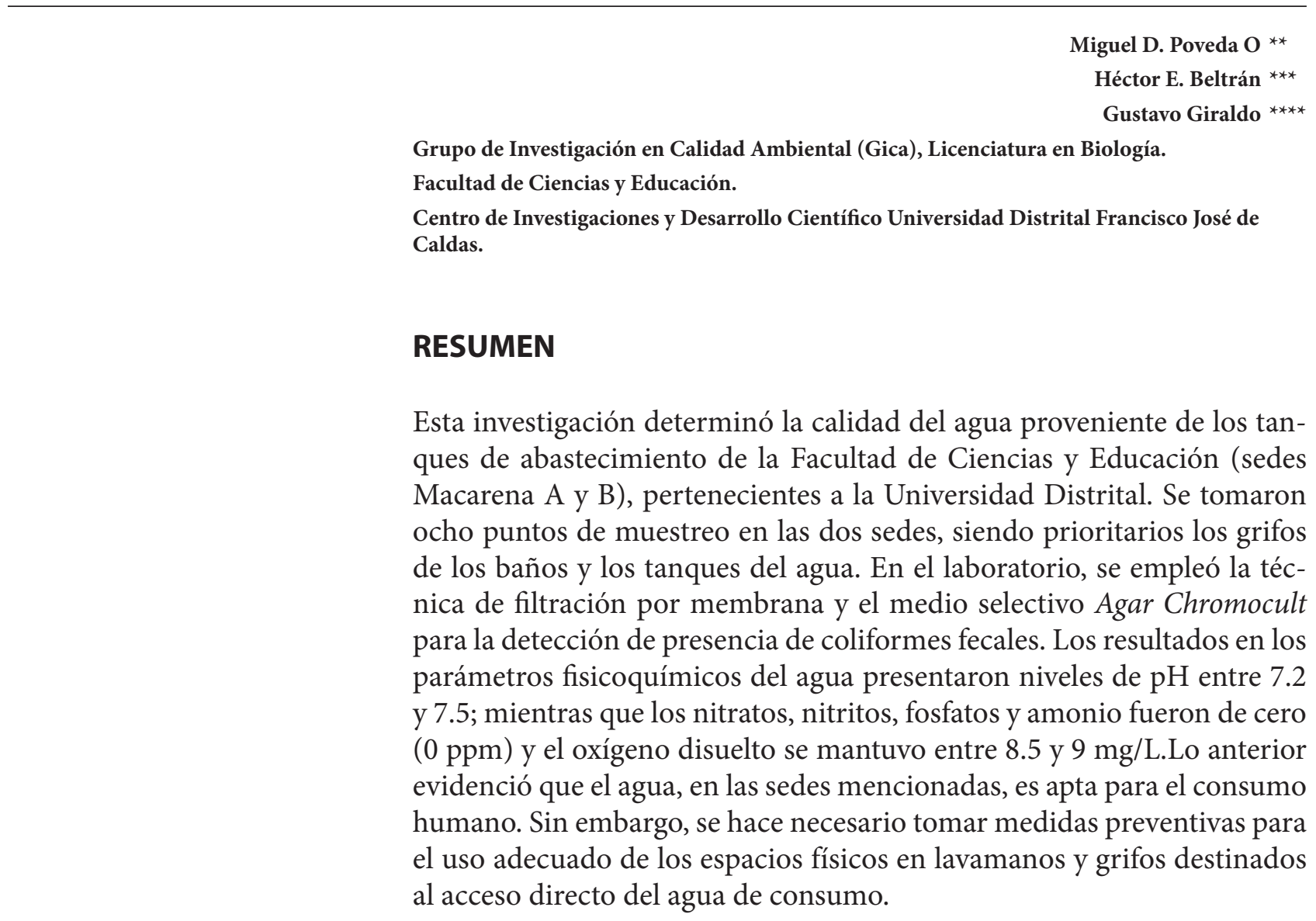

\section{PALABRAS CLAVES:}

Agua, calidad, Chromocult, bacterias, tanques, grifos, organolépticas, potabilización, E. Colí, indicadores, fisicoquímico.

* $\quad$ Proyecto financiado por el Centro de Investigaciones y Desarrollo Científico de la Universidad Distrital Francisco José de Caldas -No 2404001007.

** Director del proyecto de investigación. Licenciado en Biología de la Universidad Distrital Francisco José de Caldas, yelrad@gmail. com

*** Licenciado en Biología y docente de tiempo completo de la Universidad Distrital Francisco José de Caldas. Director y asesor del Gica.gica@udistrital.edu.co

**** Licenciado en Biología y docente de tiempo completo en la Universidad Distrital Francisco José de Caldas, Subdirector del Gica. ggiraldoq@udistrital.edu.co 
Determination of indicators of fecal contamination (fecal coliforms) in water tanks of the Universidad Distrital Francisco José De Caldas Headquarters Macarena a and $b$.

\section{Abstract}

This research determined the water quality coming from the supply tanks and the Faculty of Education headquarters Macarena $\mathrm{A}$ and $\mathrm{B}$, belonging to the University

District. It took eight sampling points in the two sites, with priority to the bathroom taps and water tanks. In the laboratory, we used the membrane filtration technique and Chromocult Agar selective medium for detecting the presence of fecal coliforms. The results for physico-chemical parameters of water presented to the $\mathrm{pH}$ levels between 7.2 to 7.5 , nitrate, nitrite, phosphate, ammonium were zero $(0 \mathrm{ppm})$, and dissolved oxygen was maintained between 8.5 and $9 \mathrm{mg} / \mathrm{L}$., which showed that the water is fit for human consumption. However, it is necessary to take preventive measures for the proper use of physical space in the sink and faucets for direct access to drinking water.

\section{Key words:}

Water, quality, chromocult, bacteria, tanks, faucets, potability, Escherichia Coli, indicators, physicochemical.

\section{Introducción:}

Durante el desarrollo de esta investigación se determinó la calidad del agua proveniente de los tanques de abastecimiento de la Facultad de Ciencias y Educación (sedes Macarena A y B) de la Universidad Distrital Francisco José de Caldas, teniendo en cuenta la prolongada permanencia de la comunidad educativa (estudiantes, docentes y personal de mantenimiento, vigilancia y aseo) y el hábito de consumir agua directamente de los grifos en los baños presentes en la facultad. Mediante la presencia de indicadores bacterianos de contaminación fecal, como coliformes fecales, fue necesario establecer si el agua procedente de éstas fuentes reúne las condiciones organolépticas para el consumo humano. El procedimiento anterior, además, fue complementado con un análisis de los parámetros fisicoquímicos ya que el agua potable -para consumo humano- se define como aquella que por cumplir las características físicas, químicas y microbiológicas, en las condiciones señaladas por el presente Decreto 1575 de 2007 y demás normas que la reglamenten, es apta para consumo humano; se utiliza en bebida directa, en la preparación de alimentos y en la higiene personal. Los coliformes son una familia de bacterias que se encuentran comúnmente en las plantas, el suelo y los animales -incluyendo a los humanos. La presencia de bacterias coliformes en el suministro de agua es un indicio de que puede estar contaminado con aguas negras u otro tipo de desechos en descomposición. Por lo general, estas bacterias se encuentran en mayor abundancia en la capa superficial del agua o en los sedimentos del fondo; no obstante, sería necesario hacer más pruebas para identificar tanto las bacterias específicas presentes como el nivel de contaminación. Los rangos recomendados de bacterias coliformes fecales por cada muestra de agua deben ser: si es potable, menos de 0 colonias/100 $\mathrm{ml}$; para la natación, menos de 200 colonias/100 $\mathrm{ml}$; y para navegar o pescar, menos de 1000/100 $\mathrm{ml}^{1}$

Siendo el Acueducto de Bogotá la empresa encargada de prestar un servicio de calidad dentro de cuyas políticas se encuentra suministrar "Agua de excelente calidad, que es un compromiso que la empresa ha atendido a cabalidad, no sólo con el fin de cumplir la reglamentación vigente, sino de suministrar un servicio confiable" (AAB, 2007), la comunidad universitaria hace uso de este servicio con la certeza del cumplimiento de la normatividad vigente para la calidad del agua por parte de esta compañía.

1 (Decreto número 1575 de 2007. Mín. Protección Social; www.ciese.org/curriculum /coliform 2007, AGUADO 1998).

REVISTA CIENTÍFICA / ENERO -DICIEMBRE DE 2010 / No. 12 / BOGOTÁ, D.C. 
Entre tanto, la variedad de microorganismos en el agua es tan elevada que se hace prácticamente imposible determinarlos por medio de análisis rutinarios y rápidos. Por ende, se recurre a la investigación de organismos que actúan como indicadores de contaminación fecal, hecho que asegura la eficacia de la potabilización y de la depuración del agua. El examen bacteriológico es un medio útil para detectar contaminaciones fecales potencialmente peligrosas en el agua y garantiza.o no la calidad de la misma -desde el punto de vista sanitario (Marin, 2003).

La técnica empleada fue la filtración por membrana. Éste método se basa en concentrar células viables sobre la superficie de una membrana y transferirla al medio de cultivo para, posteriormente, contar el número de unidades formadoras de colonias (UFC) desarrolladas luego de la incubación. En este estudio se empleó el medio Chromocult en la identificación de coliformes fecales; indica el crecimiento de Escherichia coli debido a que el substrato X-glucuronido se usa para la identificación de ß-D-glucuronidasa -característico para Escherichia coli. Éste se pega a ambos: GAL-Salmón y X-glucuronido y entonces las colonias positivas se tornan de color azul oscuro a violeta (Merck, $\left.2006^{2}\right)$.

Las variables físico-químicas del agua fueron tomadas por medio del Kit Aquamerck, un método de colorimetría que permite valorar los índices bioquímicos presentes en el agua. La temperatura de una muestra se establece por la absorción de radiaciones en las capas superficiales del líquido (ligada a la energía cinética media de sus moléculas). Por su parte, las variaciones de temperatura afectan las propiedades químicas del agua y alteran su comportamiento microbiológico. Desde el punto de vista del consumo humano, el agua es más agradable cuanto menor es su temperatura -con un óptimo situado entre $12{ }^{\circ} \mathrm{C} \mathrm{y} 16^{\circ} \mathrm{C}$. El pH del agua se debe al equilibrio carbónico y a la actividad vital de los microorganismos acuáticos. En cualquier caso, el valor de $\mathrm{pH}$ de las aguas superficiales se encuentra en el intervalo de 6.0 a 8.5 unidades.

2 Icontec (NTC 4772 y ISO 8199),
Con relación al agua potable, valores extremos de $\mathrm{pH}$ pueden provocar irritaciones en las mucosas y en órganos internos -e incluso procesos de ulceración. El Oxígeno Disuelto (OD), es la cantidad de oxígeno diluido en el agua; éste es esencial para riachuelos y lagos saludables. El nivel de OD puede ser un indicador de cuán contaminada está el agua y cuán bien puede dar soporte a la vida vegetal y animal. Generalmente, entre más alto sea el nivel de OD la calidad del agua es mejor. Por lo contario, si los niveles de OD son demasiado bajos, algunos peces y otros organismos perecerán.

Por el contrario, en aguas de consumo humano, si bien puede convenir su riqueza en oxígeno a fin de evitar fenómenos de anaerobiosis en la red de distribución, una tasa alta de $\mathrm{O}_{2}$ en tuberías puede contribuir a corrober materiales metálicos -que sirven, a su vez, como mecanismo de retroalimentación para el desarrollo de bacterias del Fe y del Mn- y provocar efectos de coloración y turbidez en el agua de consumo. Además, la cantidad de OD que puede disolverse en el agua también depende de la temperatura; una muestra de agua, entre más fría, conserva más oxígeno que una caliente. Una diferencia en los niveles de OD puede detectarse en el sitio de la prueba, pues si se realiza en la mañana, cuando el agua está fría, y luego se repite en una tarde soleada, los resultados serán diferentes.. Otra diferencia en los niveles de OD puede notarse entre las temperaturas del agua en el invierno y en el verano. Así mismo, los niveles de OD pueden variar a diferentes profundidades del agua si se presenta un cambio significativo en su temperatura.

En cuanto a compuestos, el amonio es el estado más bajo de oxidación del agua y es el destino final de la reducción de sustancias orgánicas e inorgánicas "ricas" en nitrógeno. En aguas oxigenadas, el amonio se oxida a $\mathrm{NO}_{2}$ por acción de bacterias, partiendo bien sea de amoníaco neutro o de sales de amonio monopositivo. Por otro lado, el agua de la lluvia puede presentar algunas trazas de amonio. Además, las aguas superficiales bien aireadas generalmente contienen poco $\mathrm{NH}_{3}$ (no más de 0.100 $\mathrm{mg} / \mathrm{l})$; entre tanto, las aguas contaminadas por vertidos residuales domésticos exhiben concentracio- 


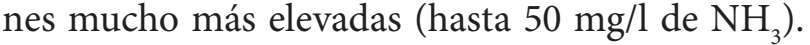
Los nitritos son poco estables químicamente y su presencia en el agua suele indicar una contaminación de carácter fecal reciente. Así pues, en aguas superficiales bien oxigenadas, la concentración de $\mathrm{NO}_{2}$ no suele superar los $0.100 \mathrm{mg} / \mathrm{l}$. Para los nitratos en aguas, el $\mathrm{NO}_{2}$ procede de la disolución de rocas y minerales (muy frecuentes), de la descomposición de materias vegetales y animales, de efluentes industriales y de lixiviar tierras en donde se utilizan abonos que los contienen profusamente como componentes en sus formulaciones. En general, las aguas naturales de la superficie no suelen contener más de $10 \mathrm{mg} / \mathrm{l}$ e incluso no se exceden de 1,0 mg/l. (Lenntech, 2003; Marin, 2003) ${ }^{3}$.

\section{Materiales y métodos:}

Fueron escogidos ocho puntos de muestreo en la Facultad de Ciencias y Educación ${ }^{4}$ de la Universidad Distrital (Sedes Macarena A y B) para verificar la calidad del agua y realizar un seguimiento durante agosto y octubre. Los lugares seleccionados (tanques de almacenamiento, abastecimiento y baños) se caracterizaron por ser de fácil acceso para las personas encargadas de la toma de muestras y el transporte de las mismas. En cuanto al análisis, se utilizaron las Guías y Normas Técnicas Colombianas para el tratamiento de muestras y almacenamiento correcto de las mismas. El estudio se basó en la GTC-100 para el manejo de muestras por medio de un control riguroso en el procesamiento; es decir, desde su toma hasta su llegada al laboratorio -aplicando, de esta forma, la cadena de custodia que consiste en verificaciones y responsabilidades en la toma de dichas muestras. Así mismo, las NTC-ISO 5667-1, 3 y 14 se utilizaron para la toma de muestras y su correcta obtención y procesamiento en el laboratorio. La siguiente tabla muestra la nomenclatura y ubicación (Tabla 1).

Los muestreos se efectuaron durante agosto, septiembre y octubre de 2007, tomando como base

3 Web: science.org/curriculum/2007.)

4 Se encuentran ubicadas en la carrera 3 \# 26a -40 de Bogotá D.C.

\section{TABLA 1. Puntos de muestreo.}

\begin{tabular}{|l|l|}
\hline MACARENA A & MACARENA B \\
\hline 1a. Tanque de abastecimiento. & $\begin{array}{c}\text { 1b. Grifo de los baños del nivel } 1 \\
\text { (laboratorios). }\end{array}$ \\
\hline $\begin{array}{c}\text { 2a. Grifo de los baños ubicados } \\
\text { en los salones superiores. }\end{array}$ & $\begin{array}{c}\text { 2b. Grifo de los baños de edificio } \\
\text { antiguo. }\end{array}$ \\
\hline $\begin{array}{c}\text { 3a. Grifo de los baños ubicados } \\
\text { en los salones inferiores. }\end{array}$ & $\begin{array}{c}\text { 3b. Tanque de abastecimiento } \\
\text { del edificio antiguo. }\end{array}$ \\
\hline $\begin{array}{c}\text { 4a. Tanque principal (con repe- } \\
\text { tición). }\end{array}$ & $\begin{array}{c}\text { 4b. Tanque principal (con repe- } \\
\text { tición). }\end{array}$ \\
\hline
\end{tabular}

los procedimientos enunciados en el Standard Methods y en las Normas Técnicas Colombianas NTC-ISO 5667-6, 5667-2, y 5667-14. . . Así mismo, se emplearon botellas de vidrio de $250 \mathrm{ml}$ previamente esterilizadas; fue necesario que el encargado de tomar las muestras y procesarlas se guiara por las medidas preventivas de bioseguridad como, por ejemplo, el uso obligatorio de guantes, tapabocas, bata y gorro (con fin de evitar cualquier tipo de contaminación que alterara en el resultado final). En cada uno de los puntos de muestreo seleccionados se llevó a cabo una observación exhaustiva de los factores externos y de todo tipo de condiciones que incidieran en la toma de la muestra -en ésta se purgó la botella con el agua del muestreo para su posterior toma. A continuación, se agregó tiosulfato de sodio $(\mathrm{Na} 2 \mathrm{~S} 2 \mathrm{O} 3 \cdot 5 \mathrm{H} 2 \mathrm{O})$ con el fin de neutralizar el cloro del agua potable -tratada por el acueducto- $y$ así permitir algún tipo de crecimiento bacteriano. Para los parámetros fisicoquímicos se hicieron dos muestreos, uno en agosto y el otro en octubre, en los tanques de almacenamiento y abastecimiento de ambas sedes, y se analizaron empleando el kit Aquamerck -1.11151.0001 (es el prototipo de la analítica móvil y puede ser usado casi en cualquier lugar sin necesidad de equipos adicionales $\left.{ }^{6}\right)$. Este es el método idóneo si los resultados se necesitan rápida, confiable y económicamente.

5 ICONTEC. NTC 4772. Calidad del agua. Detección y recuento de Escherichia coli y coliformes parte 1.

6 MERCK, Aquamerck ${ }^{\circ}$ Web: http://www.merck.com.co/ mcsa/site/wmsp.nsf/vstRefConPorTit/Aquamerck $\% 20$ \%20Quimica\%20Inicial?opendocument

REVISTA CIENTÍFICA / ENERO -DICIEMBRE DE 2010 / No. 12 / BOGOTÁ, D.C. 
Para el análisis microbiológico se empleó el sistema de filtración por membrana. Dicho procedimiento se realizó dentro de la cámara de flujo laminar (Control de Contaminación C4, Modelo CSB 120, Serie 080605 con voltaje de $220 \mathrm{~V}$ ) con objeto de reducir al máximo las posibilidades de contaminación de las muestras por otras bacterias u hongos que existieran en el ambiente. Para la filtración por membrana -o cualquier otro procedimiento con anterioridad- la cámara de flujo fue limpiada con etanol y se llevó a cabo un procedimiento de esterilización con rayos UV -durante 5 minutos- a todo el material utilizado dentro de la cámara (la radiación daña la pared de las bacterias, actuando así como un agente bactericida). Luego se tomaron $100 \mathrm{ml}$ de la muestra de agua obtenida en cada punto y se fueron agregando en la rampa de filtración (MFS) de material plástico que tiene una capacidad de $300 \mathrm{ml}$-a la cual se agregó una membrana $0,45 \mu \mathrm{m}$ (Sartorius $A G$ ) con nitrato de celulosa; es la encargada de retener el material bacteriano, eliminar los excesos y permitir, gracias al nitrógeno, el crecimiento bacteriano.

Para generar el vació dentro de la rampa se empleó la bomba de vacio (TODAY'S, Modelo Rocker 400 de $110 \mathrm{~V}, 50 / 60 \mathrm{~Hz}$ ). Las membranas, por su parte, se pusieron en cajas de petri esterilizadas (PALL, Gelman Sciences). Previamente se había preparado el Agar Chromocult de Merck para coliformes fecales, pues como primera medida se debe realizar una esterilización de los materiales a utilizar con las normas y los pasos correspondientes.

Luego se llevaron a cabo los pasos sugeridos en la etiqueta del medio de cultivo Chromocult de Merck de la siguiente manera: se tomaron $26.5 \mathrm{~g}$ de agar y fueron mezclados con $1000 \mathrm{ml}$ de agua destilada. Tras someterse a ebullición, la muestra se vertió en cajas de petri y se incubaron (Nahita Incubator, Modelo 636/13) a $44^{\circ} \mathrm{C}$ durante 24 horas. En seguida, se realizó un conteo de las unidades formadoras de colonia que se encontraban en cada punto de muestreo y se hizo una verificación con el reactivo de Kovac's para detectar la presencia del anillo rojo de indol -producido por el triptofano presente en la Escherichia Coli- para cada muestra positiva.

\section{Resultados y discusión:}

A continuación se presentan los datos fisicoquímicos registrados en agosto y octubre. Las tablas contienen los siguientes datos: $\mathrm{pH}$, temperatura, oxígeno disuelto, fosfatos, amonio, nitritos y nitratos (tomados mediante el uso de Aquamerck). Los resultados fueron obtendios en el tanque de abastecimiento de la Macarena A:

TABLA 2. Datos fisicoquímicos en Macarena A.

\begin{tabular}{|c|c|c|c|c|c|c|c|}
\hline Mes/día & 종 & ப̆ & 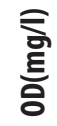 & ষ & $\begin{array}{l}\text { 을 } \\
\text { 흘 }\end{array}$ & 올 & ô \\
\hline Agosto/15 & 7 & 16 & 8 & 0 & 0 & 0 & 0 \\
\hline 0ctubre/03 & 7 & 16 & 7.5 & 0 & 0 & 0 & 0 \\
\hline
\end{tabular}

\section{GRÁFICA 1: indicadores fisicoquímicos en Macarena A.}

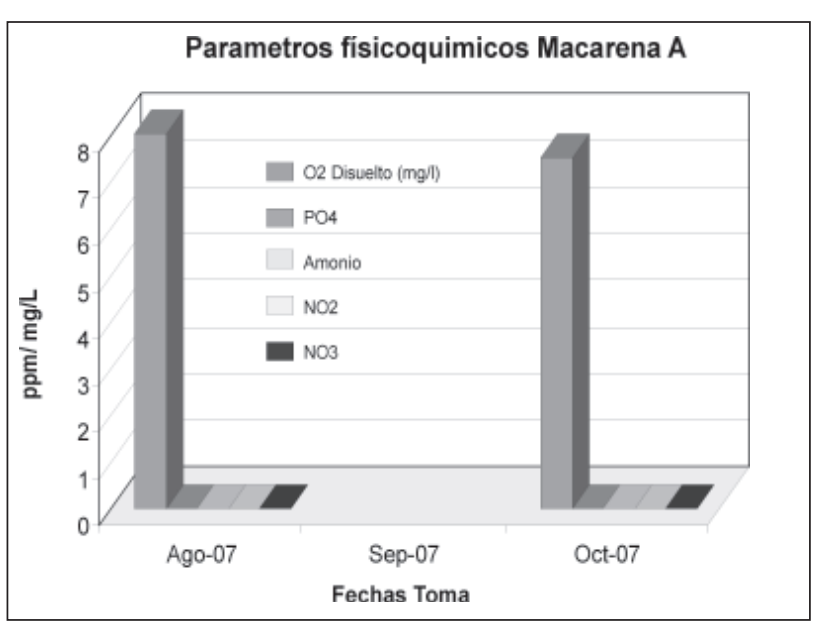

Los siguientes datos fueron registrados en el tanque de abastecimiento de la Macarena B:

TABLA 3. Datos fisicoquímicos en Macarena $B$.

\begin{tabular}{|c|c|c|c|c|c|c|c|}
\hline Mes/día & 졸 & پ & 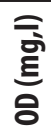 & $8^{+}$ & $\begin{array}{l}\text { 을 } \\
\text { 을 }\end{array}$ & $e^{N}$ & $\stackrel{9}{n}^{m}$ \\
\hline Agosto/15 & 7 & 16 & 9 & 0 & 0 & 0 & 0 \\
\hline 0ctubre/03 & 7 & 16 & 8 & 0 & 0 & 0 & 0 \\
\hline
\end{tabular}




\section{GRÁFICA 2: indicadores fisicoquímicos en Macarena B.}

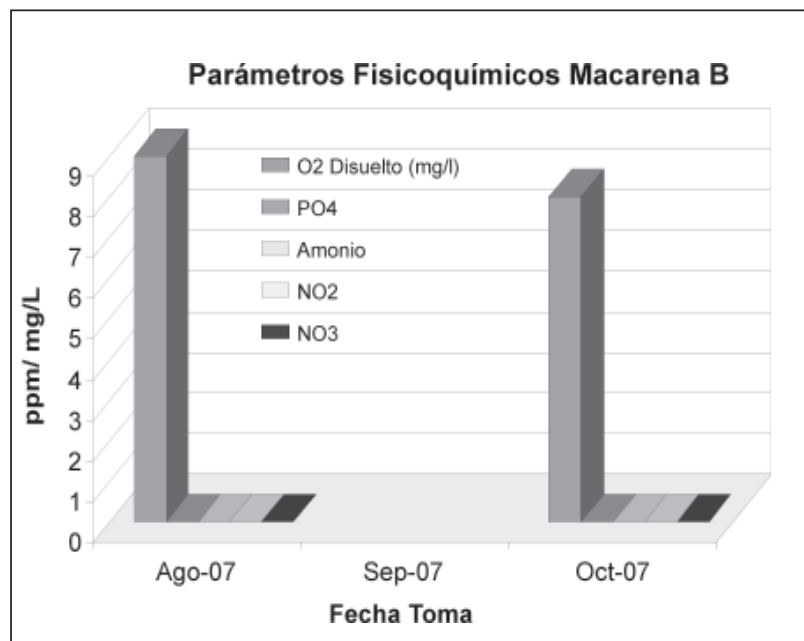

Los valores obtenidos en los parámetros fisicoquímicos (gráficas 1 y 2), permiten verificar el cumplimiento organoléptico del agua para el consumo humano en las dos sedes de la Facultad de Ciencias y Educación de la Universidad Distrital. Las características físicas mostraron que el agua evaluada en cada punto de muestreo no presentaba sólidos suspendidos ni grasas ni cuerpos extraños.

Temperatura: en cada muestreo el promedio fue de $16^{\circ} \mathrm{C}$. Sin embargo, las bacterias pueden sobrevivir a éstas temperaturas en un estado latente hasta llegar a uno hospedero que le brinde las condiciones necesarias para su desarrollo y proliferación. Rheinheimer (1990) afirma que algunas bacterias tienen la capacidad de adaptarse a diferentes temperaturas; entre ellas las enteróbacterias que son termotolerantes y se ajustan a temperaturas extremas (se encuentran en un rango entre $-10^{\circ} \mathrm{C}$ y $100^{\circ} \mathrm{C}^{7}$ ), lo que permite inferir que la temperatura no es un impedimento para el crecimiento bacteriano. No obstante, la superación de la temperatura máxima conduce muy pronto a la muerte bacteriana ya que las alteraciones sufridas por éstas afectan el protoplasma celular - dañando en la pared bacteria.

pH: las muestras de agua analizadas entre agosto y octubre,presentaron un rango de $\mathrm{pH}$ de 7.0 (neu-

7 Rheinheimer, G. (1990), Microbiología de aguas, Zaragoza, Acribia, p. 106. tro), ideal para el consumo humano e inofensivo para la salud ${ }^{8}$. El pH permite saber si el agua de consumo se encuentra dentro los rangos básicos o si, por el contrario, en rangos ácidos -aquella característica que provoca la corrosión de las tuberías de hierro- prejudiciales para la salud humana'.

Oxígeno disuelto (OD): a lo largo del estudio se presentaron niveles entre 7.5 y $9.0 \mathrm{mg} / \mathrm{l}$, que son los rangos óptimos (se encuentran entre 8 y 12 $\mathrm{mg} / \mathrm{l}^{10}$ ). El nivel de oxígeno disuelto puede ser un indicador de cuán contaminada está el agua y cuán bien puede dar soporte a la vida vegetal y animal ${ }^{11}$; con lo cual el agua suministrada por la universidad tiene un óptimo estado para su consumo. Entre tanto, de haberse presentado concentraciones inferiores a $3.0 \mathrm{mg} / \mathrm{l}$, éstas serían perjudiciales para la fauna, pues cuando existe abundante cantidad de materia orgánica, el crecimiento bacteriano se ve favorecido enormemente $\mathrm{y}$, como consecuencia, los niveles de oxígeno disuelto se reducen rápidamente a cero (Baedecker, 1980), acidificando progresivamente el medio y haciendo del agua un problema social.

Fosfatos $\left(\mathrm{PO}_{4}\right)$ : el nivel de fosfatos encontrado fue de $0.0 \mathrm{mg} / \mathrm{l}$; lo que se traduce en excelencia en la calidad de agua -su rango está entre 0.0 a $1.0 \mathrm{mg} / \mathrm{l}$. Por su parte, si se hubieran registrado valores por encima de $10.0 \mathrm{mg} / \mathrm{l}$, el agua no podría ser consumible $^{12}$. El fósforo se encuentra en aguas naturales y residuales en forma de fosfatos -un elemento esencial para el crecimiento de los organismos- y puede ser el nutriente limitador de la productividad primaria de un cuerpo en el agua. Así mismo, en cantidades superiores a $1 \mathrm{mg} / \mathrm{l}$ favorece el crecimiento de las algas. Éstas consumen el oxígeno del medio acuático y provocan la desaparición de es-

8 NORMAS OFICIALES PARA LA CALIDAD DEL AGUA COLOMBIA Op. Cit. pág. 4, disponible en Web.

9 FUNDAMENTOS PARA LA CARACTERIZACIÓN DE LAS AGUAS, Disponible en la Web

10 Disponible en http://www.k12science.org/curriculum/dipproj2/es/fieldbook/shtml

11 Ibid, disponible en la Web.

12 Ibid. disponible en la Web

REVISTA CIENTÍFICA / ENERO -DICIEMBRE DE 2010 / No. 12 / BOGOTÁ, D.C. 
pecies animales y vegetales ${ }^{13}$-como lo especifica el Standard Methods Método 4500C (1998). Por otra parte, la Resolución 2115 de 2007 expresa como valor máximo aceptable los $0.5 \mathrm{mg} / \mathrm{l}$ para fosfatos ${ }^{14}$.

Nitratos $\left(\mathrm{NO}_{3}\right)$ : pueden presentarse por escurrimiento de tierras agrícolas y pastos, aguas negras, detergentes, desechos de animales y sistemas de tuberías con fugas. El Acueducto de Bogotá mantiene un control circundante al barrio La Perseverancia (contiguo a La Macarena), que puede presentar este tipo de problemática por su gran zona boscosa. Un reflejo de este control es el resultado obtenido (0.0ppm) en las muestras de los tanques de abastecimiento de agua tanto para la Macarena A como para la Macarena B -el rango óptimo en calidad del agua es de $0.0 \mathrm{ppm}$ a $1.0 \mathrm{ppm})$. No obstante, de haberse presentado índices que sobrepasaran la concentraciones de (5.0ppm a 10ppm), se estaría presentando una contaminación del agua que afectaría a la población estudiantil y, de haber infantes, se podría presentar metahemoglobuinemia -se caracteriza por la dificultad de la sangre para absorber oxígeno ${ }^{15}$. Tal como lo especifican el Decreto 1575 del 9 de mayo de 2007 y la Resolución 2115, en las Normas y Criterios de Calidad Física, Química y Bacteriológica del Agua Potable; los nitratos tienen un valor mínimo admisible de $4.5 \mathrm{ppm}^{16}$ a $10 \mathrm{mg} / 1^{17}$. En base a lo anterior es evidente que este agua cumple con los niveles de nitratos que exige la normatividad colombiana $y$, entonces, su consumo es seguro.

Nitritos $\left(\mathrm{NO}_{2}\right)$ : los niveles reportados por este estudio fueron de $0.0 \mathrm{ppm}$, hecho que indica la óptima condición del agua proveniente del Acueducto -libre de este compuesto. Según la normatividad colombiana el valor admisible de nitritos en agua

\footnotetext{
13 Standard Methods for the examination of waster and wasterwater. Método 4500C edition20, 1998

14 Resolucion 2115 de 2007 Disponible: www.minprotección.gov.com

15 Ibid. disponible en la Web

16 Decreto 1575 de 2007. Op cit. disponible en web.

17 Resolucion 2115 de 2007. Op cit. Disponible en Web.
}

potable es de $0.1 \mathrm{ppm}^{1819}$. Sin embargo, los valores elevados son un índice de la presencia de nitrosomas en el interior de las tuberías del agua y, por lo tanto, un indicador de contaminación producto de los nitritos. ${ }^{20}$ Éstos son las formas del nitrógeno en las aguas naturales o residuales y pueden contaminar los suministros de agua debido a su uso como inhibidor de la corrosión para procesos industriales; además, el ácido nitroso, formado a partir del nitrito en soluciones ácidas, puede reaccionar con aminas secundarias dando lugar a las nitrosaminas -muchas de las cuales son agentes cancerígenos. El anterior es un parámetro fundamental que determinó la buena calidad del agua suministrada a la Universidad Distrital.

Amonio $\left(\mathrm{NH}_{4}\right)$ : las aguas superficiales bien aireadas generalmente contienen poco $\mathrm{NH}_{4}$ (no más de $0.100 \mathrm{mg} / \mathrm{l}$ ). Por su parte, las aguas contaminadas por vertidos residuales domésticos exhiben concentraciones mucho más elevadas (hasta $50 \mathrm{mg} / \mathrm{l}$ de $\mathrm{NH}_{4}{ }^{21}$ ). Las aguas evaluadas no presentaron, durante el tiempo de desarrollo del proyecto, registros de $\mathrm{NH}_{4}$-agente de contaminación antrópica de las aguas-; los niveles registrados fueron de $0.0 \mathrm{ppm}$, lo cual permite inferir que el agua presenta un nivel óptimo para su consumo.

\section{Análisis microbiano del agua:}

Los datos microbiológicos fueron obtenidos durante la totalidad del estudio, que se desarrolló entre agosto y octubre de 2007 con el método de filtración por membrana.

La Tabla 4 permite identificar las fechas de toma de muestras y los datos registrados en éstas. En azul se encuentran las cifras tomadas en la Macarena A, y en rojo las obtenidas para la Macarena B. La unidad empleada fue (UFC/ 100ml).
18 Decreto 1575, Op Cit, disponible en la Web
19 Resolucion 2115 de 2007. Op cit. Disponible en Web
20 Disponible en http: www.Lenntech.com
21 Ibíd p.3 


\section{TABLA 4. Totales. Sumatoria de datos por mes obtenidos en UFC/100ml para cada punto de muestreo.}

\begin{tabular}{|l|l|l|l|l|l|l|l|l|l|l|}
\hline FECHAS DE MUESTREOS & 1a & 2a & $\mathbf{3 a}$ & $\mathbf{4 a}$ & $\mathbf{4 a}$ & $\mathbf{1 b}$ & $\mathbf{2 b}$ & $\mathbf{3 b}$ & $\mathbf{4 b}$ & $\mathbf{4 b}$ \\
\hline Agosto 15 de 2007 & 0 & 1 & 0 & 0 & 0 & 0 & 0 & 1 & 0 & 0 \\
\hline Agosto 22 de 2007 & 0 & 0 & 0 & 0 & 0 & 1 & 1 & 0 & 0 & 0 \\
\hline Agosto 31 de 2007 & 0 & 1 & 0 & 0 & 0 & 0 & 1 & 0 & 0 & 0 \\
\hline Septiembre 08 de 2007 & 0 & 0 & 0 & 0 & 0 & 0 & 2 & 0 & 0 & 0 \\
\hline Septiembre 12 de 2007 & 0 & 0 & 0 & 0 & 0 & 2 & 0 & 0 & 0 & 0 \\
\hline Septiembre 19 de 2007 & 0 & 0 & 1 & 0 & 0 & 0 & 0 & 0 & 0 & 0 \\
\hline Septiembre 26 de 2007 & 0 & 1 & 1 & 0 & 0 & 0 & 0 & 0 & 0 & 0 \\
\hline 0ctubre 03 de 2007 & 0 & 0 & 0 & 0 & 0 & 0 & 0 & 0 & 0 & 0 \\
\hline Totales & 0 & 3 & 2 & 0 & 0 & 3 & 4 & 1 & 0 & 0 \\
\hline
\end{tabular}

\section{GRÁFICA 3. Resultados total de muestreos.}

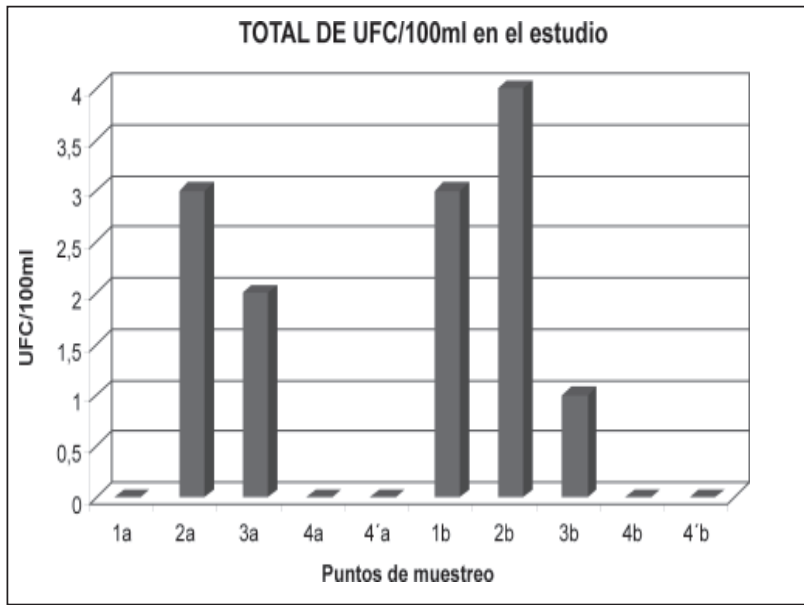

La gráfica 3 presenta los datos de crecimiento de unidades formadoras de colonias positivas para coliformes fecales (Escherichia coli) durante el estudio en cada uno de los puntos de muestreo. Estos se detectaron en los baños de ambas sedes (puntos $2 \mathrm{a}, 3 \mathrm{a}, 1 \mathrm{~b}$ y $2 \mathrm{~b}$ ) y en el tanque de almacenamiento de la Macarena B, edificio antiguo (punto 3b). Según la OMS (1987), la contaminación fecal del agua potable puede incorporar una variedad de organismos patógenos, intestinales-bacterianos, vi- rales y parasitarios cuya presencia está relacionada con enfermedades y portadores de tipo microbiano presentenes en la comunidad ${ }^{22}$.

Al emplear el agar específico para coliformes (Chromocult) se detectó la presencia positiva de estas bacterias -Gram negativas- que fermentan la lactosa a temperaturas entre $\operatorname{los} 35^{\circ} \mathrm{C}$ a $37^{\circ} \mathrm{C}$, produciendo ácido y gas $\left(\mathrm{CO}_{2}\right)$ en un lapso de 24 a 48 horas. Se clasifican como aerobias o anaerobias facultativas, son oxidasa negativa, no forman esporas y presentan actividad enzimática de la Bgalactosidasa. Además, es un indicador de contaminación microbiológica del agua para consumo humano y específico para Escherichia Coli Bacilo aerobio Gram Negativo no esporulado que se caracteriza por tener enzimas específicas como la Bgalactosidasa y B-glucoronidasa. Es el indicador microbiológico preciso de contaminación fecal en el agua para consumo humano ${ }^{23}$.

En la sede Macarena A se registraron en los baños de la planta alta de la universidad (2a) y en la planta inferior (3a) (registrando 3 y 2 UFC/100ml en cada uno). Durante los muestreos se observó que el aspecto físico de los lavamanos no era el más indicado; contenían desperdicios como: barro, tierra, cabello, alimentos y otros focos de contaminación microbiana. Por otra parte, los tanques de abastecimiento (1a) y el tanque colector de almacenamiento principal (4a) no registraron, durante este estudio, crecimiento alguno de unidades formadoras de colonia (0 UFC/100ml), lo que indica que el agua que llega a estos puntos presenta todas las condiciones bacteriológicas para el consumo humano -como lo indica la NTC 813, pues especifica que ninguna muestra de agua potable debe contener Escherichia Coli en $100 \mathrm{~cm}^{3}$ de agua ${ }^{24}$. En la Macarena $\mathbf{B}$ se presentó un estado muy similar en los baños (esto se debe al posible descuido por parte de la comunidad univer-

22 OMS 1987. Op Cit p. 3

23 Resolucion 2115 de 2007. Op cit. Disponible en Web p.1-2

24 NORMAS OFICIALES PARA LA CALIDAD DEL AGUA COLOMBIA, Pág. 4 www.cepis.ops.org/bvsacg/e/normas2/ normas-col.pdf

REVISTA CIENTÍFICA / ENERO -DICIEMBRE DE 2010 / No. 12 / BOGOTÁ, D.C. 
sitaria y otros usuarios de este servicio); durante gran parte del estudio los lavamanos contuvieron residuos sólidos a su alrededor, demostrando una falta de conciencia por parte de los usuarios con el manejo de los recursos físicos y estructurales suministrados por la Universidad Distrital.

Entre tanto, se registró un crecimiento bacteriano de coliformes fecales en el baño de los laboratorios (1b) con 3 UFC/100ml; y 4 UFC/100ml para el baño ubicado en el edificio de pedagogía (2b), siendo ambos puntos positivos para Escherichia coli y confirmadas mediante reactivo de Kovac's. En el tanque de abastecimiento de la Macarena $\mathrm{B}$, ubicado en el edificio antiguo (3b), se registró un crecimiento con una cifra de $1 \mathrm{UFC} / 100 \mathrm{ml}$ (éste no estuvo en funcionamiento durante gran parte del estudio porque se encontraba en mantenimiento; sin embargo, se hicieron las revisiones pertinentes).

El agua se encuentra empozada, sin ningún tipo de movilidad y expuesta al aire libre - permitiendo todo tipo de contaminación ambiental. Así mismo, el agua de calidad apta para el consumo humano, puede contaminarse a través de conexiones cruzadas cuando ingresa al sistema de distribución. La rotura de las tuberías y las conexiones domiciliarias defectuosas -como cisternas y reservorios-; entre otros, permiten la presencia de organismos en el agua potable que pueden causar infecciones, sobre todo en personas cuyos mecanismos de defensa se hallan disminuido -esto es más probable que suceda en gente de edad muy avanzada o muy corta, o en pacientes hospitalizados, como lo expresa la OMS $(1987)^{25}$

Así mismo, existen otras causas que predisponen el ingreso y la proliferación de microorganismos desde distintas fuentes: defectos en la construcción o en las estructuras de pozos y depósitos, y ausencia o mantenimiento irregular de dichas instalaciones (Goya, 1997). Algunos factores secundarios que permiten el crecimiento de microorganismos en el agua son: la cantidad y el tipo

25 Las Guías para la calidad del agua potable de la Organización Mundial de la Salud (OMS ) 1987. p.4-5 de nutrientes, el oxígeno, la temperatura, el $\mathrm{pH}$, la concentración del desinfectante y el material de las tuberías - el reflejo de esto se ve en el punto $3 \mathrm{~b}$, donde la caja de almacenamiento de agua se encuentra al aire libre, permitiendo la proliferación de agentes contaminantes que pueden afectar a la comunidad educativa. Por esto se hace necesario un tanque de abastecimiento de plástico como los que se encuentran en la sede Macarena A; cumplen con las normas internacionales y previenen cualquier tipo de contaminación- (Galarraga, 1984) ${ }^{26}$.

Por otro lado, la infrastrucura de la Facultad de Ciencias y Educación de la Universidad Distrital Francisco José de Caldas cuenta con problemas muy serios que afectan el desarrollo integral y la salud de los estudiantes. Uno de los más notorios es el estado paupérrimo de los baños (grifos daños, sanitarios fuera de servicio, desaeo, etc.) y la falta de conciencia de algunas personas en el cuidado y uso de estos. Los resultados positivos encontrados para Escherichia coli en los baños de las dos sedes son un indicador de contaminación que puede afectar la salud de la comunidad si no se toman las medidas preventivas para la solución de ésta problemática. De esta manera, se determinó la presencia de Escherichia coli en algunas de las muestras revisadas; el substrato X-glucuronido del medio reconoce la $\beta$-D-glucuronidasa, que es la enzima característica para Escherichia coli -une a al GAL-Salmón con el X-glucuronido ${ }^{27}$.

La Escherichia coli es causante de enfermedades como la gastroenteritis e infecciones urinarias que, como afirma Aguado $\left(1998^{28}{ }_{2}^{29}\right)$, pueden afectar a los usuarios de estos baños. Además, se realizó la prueba confirmatoria registrando un anillo de indol al utilizar el reactivo de Kovac's,; se agregó una gota de esté sobre las colonias positivas y el reactivo generó una tonalidad roja alrededor de la colonia confirmando, de esta manera,

26 Ibid, Disponible en Web.

27 MERCK, ChemDat 2007. Disponible en: www.merck. com

28 OMS 1987, Op cit p.3

29 AGUADO, Op Cit p. 3624-25 
la presencia de Escherichia coli (esto se debe a que dicho reactivo reconoce el triptofano presente en este tipo de bacterias). Los resultados positivos para coliformes fecales llevan a concluir que son producto de un posible descuido por parte de la comunidad educativa y de la falta de precaución de éstos por el manejo de las llaves suministradoras del agua y del lavamanos; permite la presencia de partículas sólidas contaminantes como tierra y pelo - visibles entorno al lavamanos. Esta puede ser una posible causa de los resultados positivos registrados en algunas de las muestras. Además, hay que tener en cuenta la poca restricción al tanque principal, ubicado en el edificio de antiguo $3 \mathbf{b}$ de la sede Macarena B; es un factor de riesgo de contaminación para este tipo de estructuras.

Finalmente, se concluyó que el agua de los tanques de abastecimiento cumple con la normatividad del Decreto 1575 y de la Resolución 2115 de 2007 tanto para el análisis fisicoquímico como para el microbiológico; no obstante, los baños presentaron algunas alteraciones por lo cual se recomienda hacer una reforma de tipo estructural: la implementación de grifos con sensor. Éstos funcionan cuando las manos del usuario entran en la zona de detección y controlan la circulación de agua del suministro durante un máximo de 30 segundos. Suponen, además, un ahorro de agua de hasta el 70\% y previenen la contaminación generada por la manipulación innecesaria de estos, hecho que genera enfermedades de tipo bacteriano en la población presente en la universidad.

\section{Agradecimientos :}

Este trabajo fue financiado por el Centro de Investigaciones y Desarrollo Científico de la Universidad Distrital Francisco José de Caldas. A los profesores HÉCTOR EDWIN BELTRÁN y GUSTAVO GIRALDO QUINTERO, por su colaboración en el desarrollo de este proyecto, y al SEMILLERO DE INVESITIGACIÓN EN CALIDAD AMBIENTAL, por la colaboración de cada uno de sus integrantes en el desarrollo y finalización de esta investigación.

\section{Referencias bibliográficas y cibergrafías:}

- Aguado, J. (1998), "Infecciones Intestinales" [en línea], disponible en: http://www.sepeap. es/libros/MEDICINE98/Artikulu/m7807. pdf, recuperado:

- Finney, M. (2003), Evaluation of Chromocult coliform agar for the detection and enumeration of Enterobacteriaceae from faecal samples from healthy subjects, Manchester, University of Salford.

- FUNDAMENTOS PARA LA CARACTERIZACIÓN DE LAS AGUAS disponible en Web 2007 UNAM.

Organización Mundial de la Salud (1995), Guías para la calidad del agua potable

Marchand, O. (), "Microorganismos indicadores de la calidad del agua de consumo humano en Lima Metropolitana" [en línea], disponible en: http://sisbib.unmsm.edu.pe/bibvirtual/Tesis/Basic/Marchand_P_E/anteced. htm, recuperado:

Marín, R. (1995), Química, microbiología, tratamiento y control Analítico de aguas, Córdoba, Servicio de Publicaciones de la Universidad de Córdoba.

Marín, R. (2003), Fisicoquímica y microbiología de los medios acuáticos. Tratamiento y control de calidad de aguas, Madrid,

Rheinheimer, G. (1990), Microbiología de aguas, Zaragoza, Acribia.,

Roldán, G. (1992), Fundamentos de limnología neotropical, Medellín, Editorial Universidad de Antioquia.

STANDARD METHODS FOR THE EXAMINATION OF WASTER AND WASTERWATER. Método 4500C edition20, 1998. 
Sitios web:

ACUEDUCTO DE BOGOTA, sitio Web: Disponible en Internet: http://www.acueducto.com. co/. Consultado el 17 de Sep. 2007.

CIESE, The Center for Innovation in Engineering and Science Education sitio Web: www.k12science.org/curriculum/dipproj2/es/fieldbook/shtml. Consultado 24 de Sep. 2007.

LENNTECH, sitio Web: www.Lenntech.com Consultado 24 de Sep. 2007

MERCK, sitioWeb:www.merck.com Consultado24 de Sep. 2007. www.merck.com.co/mcsa/site/ wmsp.nsf/vstRefConPorTit/Aquamerck ${ }^{\circledR} \% 20$ \%20Quimica\%20Inicial?opendocument
MINISTERIO DE LA PROTECCIÓN SOCIAL, COLOMBIA, Decreto número 1575 de 2007. sitio Web: Disponible en Internet: http://www. minprotección.gov.co feb. 2008. Resolución 2115 de 2007 sitio Web:Disponible: www. minprotección.gov.com

NORMAS OFICIALES PARA LA CALIDAD DEL AGUA COLOMBIA sitio Web: www. cepis.ops-oms.org/bvsacgle/normas2/normacol.pdf. feb. 2008

SEMARNAT, Secretaria del medio ambiente y Recursos Naturales, México sitioWeb:http:// www.semarnat.gob.mx/leyesynormas/Normas\%20Mexicanas\%20vigentes/NMX-AA029-SCFI-2001.pdf. Consultado el 17 de Sep. 2007. 